\title{
Facebook and Political Information in Italy and the UK: An Antidote against Political Fragmentation and Polarisation?
}

\section{Isidoropaolo Casteltrione, Queen Margaret University, UK}

\begin{abstract}
Due to the rise of digital technologies citizens can today counton innumerable and diverse sources of political information. Arguably such a proliferation of media choices in conjunction with a structural aspect of the internet, namely the presence of a pro-active and self-selecting audience, offers the conditions most conducive to selective exposure (Bimber \& Davis 2003). The tendency for selectivity of the internet audience has raised serious concerns as it maylead to a more polarised and less informed electorate (Sunstein 2001, Polat 2005, Bennett \& Iyengar 2008). However, despite many theoretical speculations, the relationship between the internet and the exposure to politically diverse information is still unclear. The present paper aims to contribute to this debate. Through a sequential explanatory mixed methods strategy, it examines the impact of Facebook on the consumption of political information in Italy and the United Kingdom and argues thatthis social networking website could reduce the risks of selective exposure and operate as an antidote against political fragmentation and polarization.
\end{abstract}

Keywords: Facebook; political information; selective exposure; accidental exposure; political fragmentation; political polarization. 


\section{Introduction}

The informative impact of the internet on today's society is certainly manifold. Digital technologieshave not only multiplied the number of information sources and the amount of available information, but they have also transformed the nature of such information by providing increasingly interactive and networked content (Hardy, Jamieson \& Winneg, 2009).Two main areas of the information environment have been particularly affected by the internet. The first relates to the flow of information which has been heavily accelerated, while the second concerns the access to information, with the online medium offering countless choices and opportunities(McNair, 2009). The current transformationsin the media and information environment, however, are not only due to the increase in available information but also to a surgein demand for information. In this regard, according to Bennet and Iyengar (2008), the internet has played a decisive role in shaping an information greedy culture. Nowadays, citizens increasingly expect accuracy, accountability and transparency from information sources, whether private or public. The internet, with its limitless capacity for content diversity and quantity (Tewksbury and Rittenberg, 2012) is the engine driving such a demand, facilitating the development of an open information environment (Milakovich, 2010).

By extension this abundance of information also applies to the realm of politics. Citizens searching for political information can access onlineinnumerable and diverse sources, from political institutions, candidates and news organisations to bloggers, video-sharing websites,non-profit organisations and private citizens (Bennet \& Iyengar, 2008; Kenski \& Stroud, 2006; Tewksbury \& Rittenberg, 2012). Cavanaugh (2000) calls the internet a political wall-mart, a single resource from which to obtain a wide variety of political information. The online medium can, in fact, complement traditional media but also operate as an alternative informative source (Calenda \& Mosca 2007).Tewksbury and Rittenberg (2009) consider these changes in the information environment an information revolution and highlight its political consequences. They note how citizens are more and more likely to use the internet to obtain political information and how, online, politically engaged citizens can take advantage of the richness of information and become more effective than ever in terms of political participation.Some academics go even further beyond and describe the internet as a potentially democratic device. Milakovich(2010) regardsthe increase of political information triggered by the internet an opportunity for the development of a more widely informed 
electorate, which is considereda major component of any healthy democratic system. Similarly,Fallows (2002) asserts that the internetbenefits democracy as it expands people's horizons exposing them to new ideas. Not only academia, but also political institutions have acknowledged the informative and democratic potential of the internet. The Committee of Ministers of the Council of Europe (2009) has, in fact, recognised that new media have improved the public access to information and that such improvement is generating better conditions for citizens' political engagement.

A voice outside this optimist chorus is Polat (2005), who identifies five factors limiting the internet's contribution to the creation of a more informed society.The first limitation is associated to the information overload. Polat stresses that humans can only process a certain limited amount of information. She refers to Percy Smith (1995), who argues that wide availability of information could negatively impact democracy as citizens may feel overwhelmed and become dependent on external institutionsfor organising and understanding such information. The second factor is the limited range and diversity of arguments resulting from media gatekeeping. Consideringhow in the U.S.major media companies such as Time Warner and AOL have invested heavily on the web and how search engines favour certain websites rather than others, Polatobserves that the internetmay not be completely immune to the power structures operating in the offline world. By the same token, Brundidge (2007) points out the elitist nature of the online information environment which she believes to be dominated by a limited number of agenda setters. However, Brundidge recognizes that such agenda setters are not necessarilyassociated withmajor political parties and media and, consequently, do not always duplicate offline power structures.The third limitation is the unequal distribution of resources. Polat argues that on balance the internetbenefits people who are already in a better position in terms of skills, income and physical access to political information. The fourth limitation is related tohow internet users differ in terms of motivations and web usages. To back up her argument Polat considers the study of Shah,McLeod and Yoon(2001) showing that people with low education tend to use the internet mainly for entertainment while better educated people employ the internetmore for informationalpurposes. The third and fourth limitations are linked to Tichenor, Donohue and Olien's (1970)knowledge gap theory. Bimber (2003) applies this theoretical frame to the online environment and concludes that the internetcould widen the gap between information rich and information poor.Finally, the fifth limitation identified by Polat and also recognised 
by Bimber (2003) is the tendency of selective exposure of internet users which can generate fragmentation and lead to a polarised society lacking of shared knowledge.

This paper focuses on this latter aspect, namely the potential of the internet to promote selective exposure. The theory of selective exposure finds its roots in Festinger's (1957) cognitive dissonance theory and suggests that to elude cognitive discomfort individuals tendto expose themselves to pro-attitudinal information while avoiding conflicting perspectives (Klapper, 1960).To date these theoretical claims have received mixed support (Brundidge, 2007).As reported by Holbert, Garrett, and Gleason (2010, pp. 19-20), there are studies challenging the premise that ideological homogeneity is psychologically desirable (Frey 1986) and arguing that selective exposure does not necessarily lead to the avoidance of attitude-discrepant information (Chaffee, Saphir, Graf, Sandvig \& Hahn, 2001; Garrett, 2009; Webster, 2007).In the last decade the changes occurred in the information environment have brought renewed attention to the issue of selective exposure. According to Bimber and Davis (2003), the internet offers the conditions most conducive to selective exposure. This is dueto two of its structural aspects. The first is the abundance of information and the consequent proliferation of media choices. Bennet and Iyengar (2008) talk of a shift from information commons to informationstratamentation. They argue that fifty years agoit was possible to talk of information commons as information provided by news organisation was extremely homogeneous and standardised. The rise of the internet and the resulting proliferation of media choices have lead to fragmentation of the information environment. This new information regime (Bimber, 2003) is characterised by informationstratamentation, namely a combination of segmentation and fragmentation of information (Bennet \& Iyengar 2008). Tewksbury and Rittenberg (2009) believe that specialization, segmentation, fragmentation and polarization are inter-related phenomena. They describe specialization as the tendency of some individuals to focus on certain topics or the disposition of sites to tailor their content to specific audiences. In their view, the specialization of news exposure has generated the segmentation of audiences and, ultimately, fragmentation which is defined as "the lack of widespread public exposure to some content of interest" (p. 196). They argue that a fragmented information environment is prone to polarization which occurs when audience groups consume idiosyncratic content. Tewksbury and Rittenberg developed an interesting argument and claim that by providing "too much freedom", by enabling users to focus on content and activities which are relevant to them, the internet can lead to selective exposure 
and the exclusion of counter-attitudinal political information. The second structural aspect is the presence of a pro-active and self-selecting audience. The active role of the audience in content selection and consumption is, in fact, a necessary condition to the occurrence of selective exposure (Dutta-Bergman \& Wonjun, 2005). Thiscontrol could induce segmentation as individuals may select only the information strengthening their existing position (Anduiza, Cantijoch \& Gallego, 2009). The tendency for selectivity of the internet audience is an area of concern for certain academics who believe that this phenomenon will progressively lead to a more polarised and less-informed electorate (Sunstein 2001, Polat 2005, Bennett \& Iyengar 2008). One of most prominent advocates of this position is Sunstein (2001) who suggests that in the onlineenvironment individuals tend to operate in eco-chambers interacting with likeminded users.

Despite many theorisations the relationship between the internet and the exposure to politically-diverse information is, today, still unclear. Some research supports the argument that the internet increasingly exposes individuals to pro-attitudinal perspectives. For instance, Bimber and Davis (2003) analysed the audiences of campaign websites during the 2000 U.S. presidential election and conclude that when compared with television and newspapers the internet provides the conditions most conducive to selective exposure. Adamic and Glance (2005) study thelinks among the posts of a series of blogs and show that Liberal blogs linked primarily to other Liberal blogswhile the opposite happens for Conservative blogs.Similarly,Stroud (2008) establishes that people's political beliefs relate to their media exposure, both online and offline. These findings are confirmed by Nie, Miller, Golde, Butler and Winneg (2010) who demonstrate that online consumers expose themselves to news content in line with their own political views. On the other hand,there is a strand of research asserting that internet users can brake away from the dynamics of selective exposure through accidental exposure to information. Brundidge (2010) speaks of inadvertency and argues that in theonlineenvironmentindividuals are exposed to more political difference than they would be otherwise, even if only inadvertently. The inadvertency thesis is supported by several studies. As highlighted by Brundidge (2010, p. 685), Wojcieszak and Mutz (2009) observe that the exposure to counter-attitudinal political messages is more likely to happen in nonpolitical chat rooms. Accordingly, Cornfield (2005) finds that 36 percent of internet users claim toget campaign news and information not through a directed search but accidentally, while surfing the web for different purposes.According to Tewksbury, Weaver and Maddex 
(2001), the traditional mass-media models of news dissemination may not be applicable to the internet because onlineaudiencesacquire information even when they are not deliberately looking for it. Traditional models, in fact, conceptualize news exposure as an intentional processwhereasinternet users can obtain information in an incidental fashion, as "a byproduct of their other online activities" (Tewksbury et al., 2001, p. 533).

Among the various internet tools, social networking websites (SNSs) appear to be particularly prone to accidental exposure (Baresch, Knight, Harp \& Yaschur, 2011). SNSs can be defined as "web-based services that allow individuals to (1) construct a public or semi-public profile within a bounded system, (2) articulate a list of other users with whom they share a connection, and (3) view and traverse their list of connections and those made by others within the system" (Boyd \& Ellison, 2007, p. 211). Because of the increasing possibilities of sharing contentoffered by SNSs many internet users organize and obtain their news via their social networks (Baresch et al. 2011). Research has attested to the political relevance of SNSs and found that one of the main motivations behind their usageis to gather political information (Rainie \& Smith, 2011). Lerman and Ghosh (2010) analyse the mechanisms of news diffusion on SNSs and speak of information contagion. By means of sharing, liking, retweeting, accidental exposure to information can occur as individuals do not always choose what to consume and information is often presented to them.SNSs' users could, therefore, evade selective exposure which relies on the active role of the audience and encounter political difference. An, Cha, Gummadi and Crowcroft (2001) confirm this theory and find that on Twitter there is a non-negligible amount of indirect media exposure which expands the diversity of news users are exposed to. Similar results emerge from the investigations of Vickery (2009) and Kim (2011) whoestablish that SNSs can enable exposure to cross-cutting opinions.On the contrary, in a qualitative content analysis of Facebook posts, Meyer (2012) observes that in the U.S. Republicans and Democrats have built highly partisan social media communities and that selective exposure can take place also on SNSs. Taking into account the academic literature presented so far,a mixed picture emerges with regards to the tendency of selective exposure of internet users. This state of affairs calls for further research particularly in relation to SNSs, an environment where accidental dynamics strongly intervene upon the flow of information. 


\section{Methodology}

This paper has been drawn from a larger mixed-methods study investigating the impact of Facebook on political participation in Italy and the United Kingdom. Among the various mixed-methods strategies, this investigation has employed a sequential-explanatory approach characterised by a first quantitative phase and a subsequent qualitative phase. In the first phase,a web-based survey explored the links between citizens' Facebook political participation, internet political participation (excluding Facebook activity) and offline political participation. Information from the first phase has been further examined in the second qualitative stage where a series of semi-structured interviews were held. The purposeof the qualitative phase is to build uponthe initial findings and to examine the mechanisms responsible for producing the identified associations.

\section{Sampling}

A pragmatic approach has been applied to sampling. The target populations of this investigation arethe British and Italian Facebook populations minus the 13-17, and 65+ years old age groups. The 13-17 years old age group has been excluded from the study in order to avoid ethical issues. The $65+$ age group has not been taken into consideration as, in both countries, it represents a very small fraction of the total Facebook population and finding participants fitting within this category could have proved particularly problematic.

A stratified-snowball sampling strategy has been adopted to recruit respondents for the online surveys. This strategy entailsan initialchain-referral recruitmentstage andthe random selection of the final sample through the application of a post-stratifying criterion (i.e. age). Age has been chosen as post-stratifyingcriterion because of its relevance to the political participation phenomenon (see Quintelier, 2007 for a detailed account). From the initial 483 participants 196 participants for the British sample (BS) and 196 participants for the Italian sample (IS) were selected. For the qualitative phase a total of 26 interviews (13 for the BS and 13 for the IS) were held. A subset of the survey participants waschosen for the qualitative stage.The selection of the sub-sample occurred according to several criteria such as the identification of particularly significant quantitative results, unexpected non-significant quantitative results, extreme cases, demographics, characteristics, and self-interest.Because the sub-sample did not provide participants with certain characteristics (e.g. political activists between the age of 18- 
24 willing to be interviewed) a number ofqualitative participants (i.e. 4 for the BS and 3 for the IS) were selectedthrougha further snowballing procedure.

\section{Information Activities}

The study this paper has been drawn from conceptualises political participation as a multidimensional phenomenon which encompasses under its umbrella three different typologies of participatory activity: campaign activities (e.g. soliciting others to support or oppose a particular political party, candidate, and initiative); contact activities (e.g. contacting a political party, candidate, government department and/or local council); and communication activities (e.g. consumption of political news). This paper focuses on communication activities which Christy (1987) describes as a form of political participation not channelled through political institutions and reflecting a more individual interest and psychological involvement in politics. Three activities related to the consumption of political information have been considered in this paper: learning about a political initiative, meeting, rally and/or protest;learning about a group or an organisation developed around politics; and consumption of political news.Each of the activities has been assessed through a five-point frequency scale (1=Never, 2=Rarely, 3=Sometimes, 4=Often and 5=Very Often). Participants were asked how often in the last six months they engaged in the first two activities through Facebook, through the internet(excluding Facebook activity) and watch/listen/read political newson Facebook, on the internet, on TV, on the radio and on the press. In addition, three summated-rating scales:FacebookPoliticalInformation,InternetPolitical Information and OfflinePolitical Information, were generated adding the scores of the various survey items, with each item bearing equal weight.

\section{Data Analysis}

Considerations on the nature of the samples and of the data have guided the selection of the statistical tools for the quantitative data analysis. In a political participation study Calenda and Mosca (2007) explain that samples characterized by strong non-probabilistic components cannot produce strong inferences and descriptive statistical tools are to be preferred. Accordingly, given the purposive and pragmatic nature of this study's samples, descriptive statistics have been employed to analyze the quantitative data. The most appropriate statistical tools have been chosen taking into consideration the distribution of the data. The Kolmogorov-Smirnov test with Lilliefors correction, which is best used for sample sizes of 
more than 50, with unknown population mean and variance (Lilliefors 1967), was run to assess the normality of the distributions of scores. The test established that the data is not normally distributed (p. < 0.05) and, consequently, medians rather than means have been employed as measures of central tendency.

Table I - Test of normality

\begin{tabular}{|lll|c|c|c|}
\hline \multirow{2}{*}{ Nationality } & & & \multicolumn{3}{|c|}{ Kolmogorov-Smirnov ${ }^{\mathrm{a}}$} \\
\cline { 4 - 6 } & & & Statistic & $\mathrm{df}$ & Sig. \\
\hline Sritish & Facebook & Information & .158 & 196 & .000 \\
& Activity & & & & \\
& Internet & Information & .130 & 196 & .000 \\
& Activity & & & & \\
& Offline & Information & .120 & 196 & .000 \\
& Activity & & & & \\
\hline Italian & Facebook & Information & .095 & 196 & .000 \\
Sample & Activity & & & & \\
& Internet & Information & .119 & 196 & .000 \\
& Activity & & & & \\
& Offline & Information & .097 & 196 & .000 \\
& Activity & & & & \\
& & & &
\end{tabular}

${ }^{\mathrm{a}}$ Lilliefors significance correction

The qualitative data have been examined through a thematic analysis. A number of thematic categories have been developed in order to examinehow selective exposure operates on Facebook(Table II). The themes were established taking into consideration the academic literature (i.e. prior research code development) and the questionnaire's results. Finally, the themes were reviewed and revised during the analysis ofthe qualitative content (i.e. datadriven code development). This three-step process can be described as theory-driven coding (Boyatzis, 1998). 
Table II - Content analysis themes

\begin{tabular}{|l|l|}
\hline \multirow{5}{*}{ Themes } & Sub-themes \\
\hline Selective Exposure & Facebook Selective Exposure \\
\cline { 2 - 2 } & $\begin{array}{l}\text { Facebook Exposure to Counter-attitudinal } \\
\text { Information }\end{array}$ \\
\cline { 2 - 2 } & Active Selection of Information \\
\cline { 2 - 2 } & Accidental Exposure \\
\hline Facebook Contacts & Political Contacts \\
\cline { 2 - 3 } & Non-political Contacts \\
\cline { 2 - 3 } & Politically Heterogeneous Contacts \\
\cline { 2 - 3 } & Politically Non-heterogeneous Contacts \\
\hline Political Engagement & Interest in Politics \\
\cline { 2 - 3 } & Interest in Contrasting Views \\
\hline
\end{tabular}

\section{Results}

The current paper aims to assess whether Facebook could operate as an antidote against political fragmentation and polarization. In order to do so both the relevance of Facebook as a political information source and its capability to facilitate the exposure to counter-attitudinal information have to be addressed. The first issue has been examined through the quantitative data while the qualitative results have been employed to explore the second matter.

\section{Quantitative Results}

From the quantitative results it emerges that in the BS the most used channel for each of the considered information activities is the internet whileFacebook and offline related activities display identical scores. In the IS,Facebook is the most used political information channel, followed by the internetand the offline world. In terms of intensity of activity, the BS displays low scores in relation to the consumption of political information whereas the IS shows a moderate consumption. These results are also confirmed when the Facebook, Internet and Offline Political Information scales are taken into consideration. 
Table III - Information activities

\begin{tabular}{|c|c|c|c|c|c|c|}
\hline & \multicolumn{6}{|c|}{ Nationality } \\
\hline & \multicolumn{3}{|c|}{ British Sample } & \multicolumn{3}{|c|}{ Italian Sample } \\
\hline & \multicolumn{2}{|c|}{$\mathrm{N}$} & \multirow[b]{2}{*}{ Median } & \multicolumn{2}{|c|}{$\mathrm{N}$} & \multirow[b]{2}{*}{ Median } \\
\hline & Valid & Missing & & Valid & Missing & \\
\hline $\begin{array}{l}\text { Learning about a political } \\
\text { initiative, meeting, rally and/or } \\
\text { protest on Facebook }\end{array}$ & 196 & 0 & 1 & 196 & 0 & 3 \\
\hline $\begin{array}{l}\text { Learning about a political } \\
\text { initiative, meeting, rally and/or } \\
\text { protest on the internet }\end{array}$ & 196 & 0 & 2 & 196 & 0 & 2 \\
\hline $\begin{array}{l}\text { Learning about a political } \\
\text { initiative, meeting, rally and/or } \\
\text { protest offline }\end{array}$ & 196 & 0 & 1 & 196 & 0 & 2 \\
\hline $\begin{array}{l}\text { Learning about a group or an } \\
\text { organisation developed around } \\
\text { politics on Facebook }\end{array}$ & 196 & 0 & 1 & 196 & 0 & 3 \\
\hline $\begin{array}{l}\text { Learning about a group or an } \\
\text { organisation developed around } \\
\text { politics on the internet }\end{array}$ & 196 & 0 & 2 & 196 & 0 & 2 \\
\hline $\begin{array}{l}\text { Learning about a group or an } \\
\text { organisation developed around } \\
\text { politics offline }\end{array}$ & 196 & 0 & 1 & 196 & 0 & 2 \\
\hline Facebook consumption of & 196 & 0 & 3 & 196 & 0 & 4 \\
\hline
\end{tabular}




\begin{tabular}{|c|c|c|c|c|c|c|}
\hline political news & & & & & & \\
\hline $\begin{array}{l}\text { Internet consumption of political } \\
\text { news }\end{array}$ & 196 & 0 & 4 & 196 & 0 & 4 \\
\hline $\begin{array}{l}\text { TV consumption of political } \\
\text { news }\end{array}$ & 196 & 0 & 3 & 196 & 0 & 4 \\
\hline $\begin{array}{l}\text { Press consumption of political } \\
\text { news }\end{array}$ & 196 & 0 & 3 & 196 & 0 & 3 \\
\hline $\begin{array}{l}\text { Radio consumption of political } \\
\text { news }\end{array}$ & 196 & 0 & 3 & 196 & 0 & 3 \\
\hline $\begin{array}{l}\text { Offline consumption of political } \\
\text { news }\end{array}$ & 196 & 0 & 3 & 196 & 0 & 3.33 \\
\hline
\end{tabular}

1= Never, 2= Rarely, 3 = Sometimes, 4= Often, 5= Very often

Please note that offline consumption of political news is an average measure generated from $\mathrm{TV}$, radio and press consumption of political news

TableIV - Facebook, internet and offline political information activity

\begin{tabular}{|c|c|c|c|c|c|c|}
\hline & \multicolumn{6}{|c|}{ Nationality } \\
\hline & \multicolumn{3}{|c|}{ British Sample } & \multicolumn{3}{|c|}{ Italian Sample } \\
\hline & \multicolumn{2}{|r|}{$\mathrm{N}$} & \multirow[b]{2}{*}{ Median } & \multicolumn{2}{|r|}{$\mathrm{N}$} & \multirow[b]{2}{*}{ Median } \\
\hline & Valid & Missing & & Valid & Missing & \\
\hline Facebook Political Information & 196 & 0 & 6 & 196 & 0 & 9 \\
\hline Internet Political Information & 196 & 0 & 7 & 196 & 0 & 8.50 \\
\hline Offline Political Information & 196 & 0 & 6 & 196 & 0 & 7.83 \\
\hline
\end{tabular}


$3=$ Never, $6=$ Rarely, $9=$ Sometimes, 12= Often, 15= Very often

In summary, the data indicate that in the BS Facebook is employed to obtain political information as much as traditional media but less than the internet, whereas in the IS Facebook is the major political information channel. These results demonstrate the relevance of Facebook as a political information sourceand are in line with the several studies investigating the impact of Facebookon the diffusion of political information. Hermida, Fletcher, Korrell and Logan (2011) find that two-fifths of SNSs users get the news from people they follow on websites such as Facebook, while a fifth obtain news from news organizations and individual journalists they follow. They conclude that SNSs are a significant source of news. Similarly, in Vickery's (2009) qualitative study all participants cite Facebook as a major source of political information and many participants claim to have discovered new sources of news through the links their friends post on Facebook. According to Vickery (2009) these results are indicative of a larger trend in which an increasing number of people are using SNSs as news aggregators. However, Facebook's relevance as political information source is not unanimously recognized in academia. For instance, in a recent study, Lampe, Vitak, Gray, and Ellison (2012) observe that Facebook users were not likely to use this SNS to seek information. According to them, this suggests that users may still perceiveFacebook mainly as a social tool.To evaluate the potential of Facebook to counteract the fragmentation and polarization trends the penetration of this SNS has also to be considered. In relation to the two countries this paper focuses on, Facebook has 51.61 per cent penetration of the total British population and 61.02 per cent of the British online population. In Italy Facebook's penetration is even lower with regards to the total population, 38.16 per cent, while is slightly higherforthe Italian online population, 70.85 per cent (Socialbakers, 2013). This data shows that Facebook is not yetuniversal.In this sense, it would be possible to talk of a Facebook divide which may limit this SNS' contributions and relevance to society.

\section{Qualitative Results}

Facebook's ability to reduce selective exposure has been assessed through the qualitative data. In particular, this paper explores the thesis that Facebook users may be inadvertently exposed to counter-attitudinal political information. As these statements illustrate, from the interviews it appears that in both samples it is common for Facebook users to acquire politically-diverse information: 
"you will find people who will post the same article you would come across on a website or TV or whatever, but you would also find a larger variation. So you would find news from websites you may not know they exist or you may hadnever come across. So the participation of so many people means that you get a larger net cast [...]. I read stuff from sites that I wouldn't have known even that existed if a friend or another person, a friend of friend, hadn't found it and posted it" (BS)

“(On Facebook) I've crossed people with completely opposing views" (BS)

"Facebook has no filters. I have more than 1000 contacts [...] I know the political views of $20 \%$ of those contacts while I have no idea for the rest. Sometimes I see links and click on them. Therefore, (on Facebook) you have a surplus of news which comes from everywhere" (IS)

"I have two, three (Facebook) contactsthatare located righton the opposite (political) side. Clearlythey posttheir contentvirally" (IS)

Tewksbury and Rittenberg (2012) describe the online consumption of news and political information as a multistep process. Online audiences can purposively select political information but also be accidentally exposed to it. As mentioned in the Introduction section, active selection is a necessary condition for the occurrence of selective exposure. On Facebook, people who are interested in politics can follow political pages and news organizations or even be members of political groups. In this case,Facebook users proactivelyselect informative sources and, as a consequence, selective exposure may take place. In both samples the interviews confirm that the Facebook environment isnot immune to the dynamics of selective exposure.However, the qualitative data also show thatactive selection of information does not lead automatically to selective exposure. In accordance with Frey's (1986) argument that ideological homogeneity is not psychologically desirable, individuals interested in politics may, in fact, also search for politically-diverse information: 
" $80 \%, 90 \%$ of the time I look (for political information) in (politically) contiguous settings. However, I understand that on certain issues I need also to see how different political forces think and act" (IS)

Facebook users can also access political information through an accidental route. Facebook's News Feed plays a crucial role in this accidental exposure.The News Feed, which appears on each user's homepage, performs an information based function. It simplifies and accelerates the sharing of information by showing a constantly updated list of friends and pages'activities (Vitak, Zube, Carr, Ellison \& Lampe, 2009).Among the various Facebook's features, arguably, the News Feed provides users with the greatest opportunities in terms of political information. This could be possibly related to the lack of active selection in the consumption of political information. The News Feed enables users to passively view activities of their network (Lampe et al. 2012).Individuals are drawn to the activities within their networks and no longer have to seek out information, but rather the information is presented to them whenever they access the site (Vickery 2009). The thesis of information contagion developed by Lerman and Ghosh (2010) is supported by the findings of this study. Both British and Italian participants, in fact, talk of the extended, viral nature of the Facebook information environment:

"people are subjected to more articles, a wide variety, instead of flicking pass the news, on Facebook a headline comes up..." (BS)

"sometimes you get shared stories or shared posts that circulate among friends and you get thousand of people liking them." (BS)

"It's like when you go fishing. Instead of using one fishing rod you use many as there are the news I get and the news my contacts get. Therefore, there is an invasion of news" (IS)

"It is a sort of media contagion. Information and communication travel on increasingly extended tracks: the information that should go from $A$ to $B$ is read by $C$, a third individual who interacts with A. Consequently, new connections are born according to the topics rather than people's will" (IS)

Participants alsoconfirm that users may be inadvertently exposed to political difference: 
"I read stuff from sites that I wouldn't have known even that existed if a friend or another person, a friend of friend, hadn't found it and posted it" (BS).

"I didn't particularly seek out (contrasting political information) you but now, sort of, it comes to me." (BS)

"I would say that Facebook has certainly increased my knowledge. It had the effect of widening my information sources [...] Facebook posts (information) as soon as you access. Even if you don't want you see this information. Therefore, because this information is imposed, in the sense that you don't look anymore for information but the information is there and you see it, [...] your information is widened in comparison to the past" (IS)

Not all Facebook users are, however, able to gain access to counter-attitudinal political information through the accidental route.To bypass selective exposure a politically interested and politically-heterogeneous network of contacts is required. The relevance of the Facebook network for the information gathering process has been stressed by Vickery (2009) and Lampe et al. (2012). The first states that the level of political involvement of the network strongly influences the degree of exposure to political information while Lampe et al. (2012) claim that users with larger and more diverse networks should obtain more non-redundant information. The presence of politically heterogeneous contacts is not enough to be exposed to political difference.Interaction with such contactsis also needed asThe News Feeddisplaysonly activities relevant to the user. The relevance of an activity is established through an algorithm (i.e. EdgeRank) based on various parameters, among which users' previous behaviours. This means that if a user does not interact with a contact over a certain period of time, this contact's activities will stop appearing in the News Feed. Consequently, as highlighted by a British participant, due to the EdgeRank algorithm lack of interaction could lead to selective exposure:

“(On Facebook) I guess I do get a certain (political) range but not that bigger range. Partly because Facebook tends to hide from me the people I don't interact with. Facebook hides from you people who you didn't interact with recently. So there are probably people 
who have different political views to me but I don't really talk to them very much on there" (BS)

This paper develops a model explaining the dynamics of selective exposure in the Facebook environment. According to this model, called the Dual Routes of Exposure Model, Facebook's consumption of political information can occur through two routes: the direct route and the accidental route. In the direct route users have control over the flow of information and actively select information according to personal preferences, interests and habits. Due to this active selection of content selective exposure may take place. The direct route, however, does not lead necessarily to selective exposure as users may purposively consume politically diverse information.

In the accidental route users are passively and inadvertently exposed to information. Like the previous route, this can lead to the exposure to both reinforcing and counter-attitudinal content. The first can occur if users interact excursively with not politically interested orpolitically contiguous contacts. Conversely, in the presence of a politically interested and politically heterogeneous network, Facebook users may bypass selective exposure and acquire counter-attitudinal political information.

Figure I - Facebook and Selective Exposure: The Dual Routes of Exposure Model

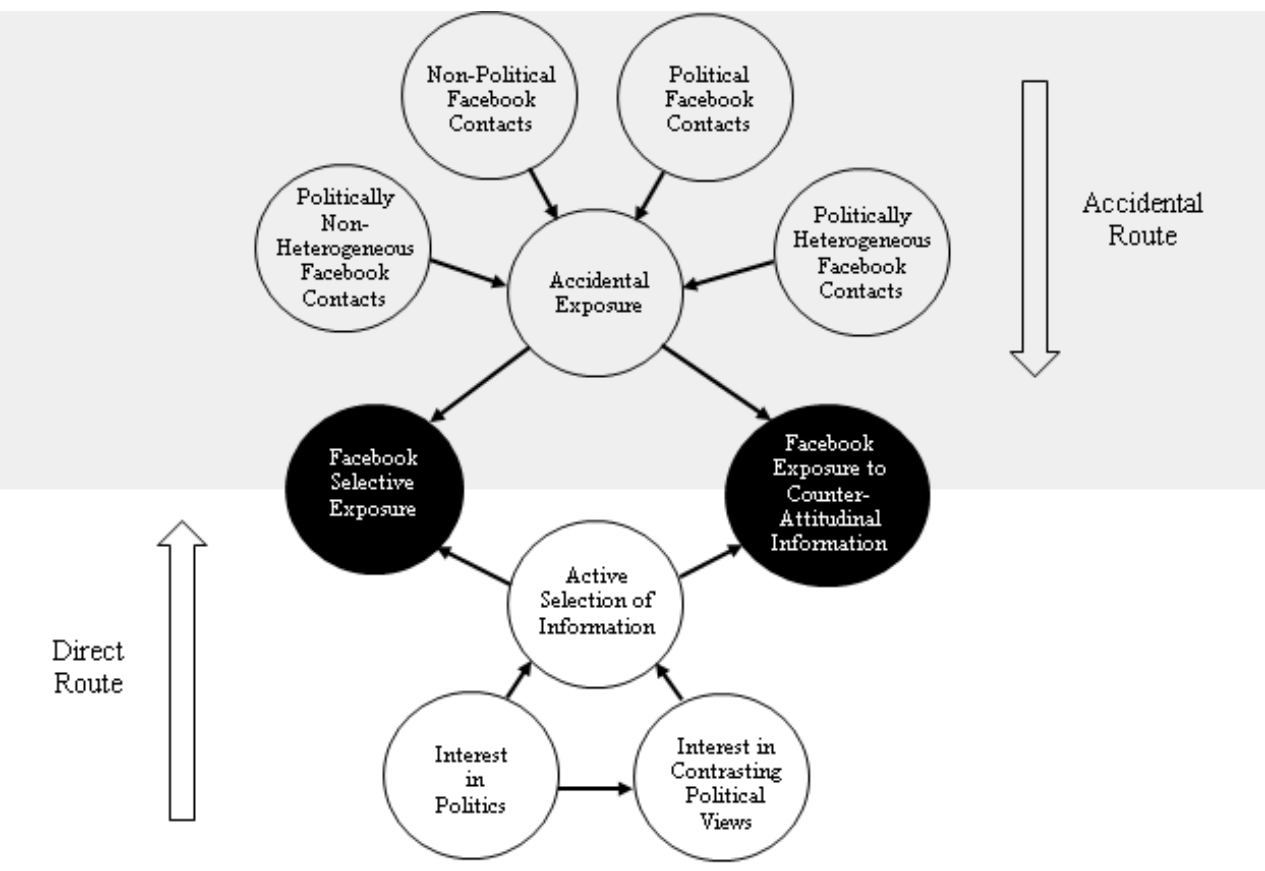




\section{Conclusions}

This paper contributes to the strand of research investigatingthe relationship between the internet and the phenomenon of selective exposure. Focusing on the case of Facebook, it provides evidence in support of Brundidge's (2010) inadvertency thesis.In theFacebook environmentaccidental dynamics strongly intervene in the diffusion of political information and users may be inadvertently exposed to political difference. Active selection is a necessary condition for the occurrence of selective exposure but on SNSs thediffusion of information is both an intentional and incidental process. Through what has been labelled by Lerman and Ghosh (2010) as information contagion, users are presented with new opportunities to heterogeneously expand their social and information networks. As a result, the formation of eco-chambers, where users will interact only with like-minded individuals (Sunstein, 2001), appears less probable onFacebook. Hermida et al. (2011)report that SNSs are particularly valued information sources as they facilitate the exposure to a wider range of news and information. Accordingly, this study finds that Facebook enables the access to politically diverse content. This, however, may not be enough to counter the polarisation and fragmentation trends characterising the internet. Facebook is, in fact, not immune to selective exposure and accidental exposure to counter-attitudinal perspectives is only a component of the information consumption process. Academics celebrate Facebook's ability to provide a much larger sphere of potential influence for opinion leaders and opinion followers than other media environments (Zube,Lampe \& Lin, 2009). In line with several studies addressing SNSs' political relevance (Rainie\& Smith, 2012; Rainie, Smith, Lehman-Schlozman, Brady \&Verba, 2012; Vickery, 2009), this paper confirms that Facebook is a relevant source of political information. At the same time, it recognises that Facebook is not a universal tool. The existence of ausage gap which could be described as Facebook dividelimitsthe impactof this SNS on society.In conclusion, Facebook is a potential antidote against political fragmentation and polarisation but its contributionto the formation of a more widely-informed electorateis yet to be established. 


\section{References}

Adamic, L. A.\& Glance, N. (2005). The political blogosphere and the 2004 U.S. election: divided they blog. In LinkKDD '05: Proceedings of the 3rd internationalworkshop on Link discovery, 36-43. doi:10.1145/1134271.1134277

An, J., Cha, M., Gummadi, K., \&Crowcroft, J. (2011). Media landscape in Twitter: A world of new conventions and political diversity. Proceedings of $5^{\text {th }}$ International Conference on Weblogs and Social Media [online]. Menlo Park, California: The AAAI Press. Available from www.aaai.org.

Anduiza, E., Cantijoch, M. \&Gallego, A. (2009). Political Participation and the Internet: A Field Essay. Information, Communication \& Society, 12 (6), 860-878. doi:10.1080/13691180802282720

Baresch, B., Knight, L., Harp, D., \&Yaschur, C. (2011). Friends who choose your news: An analysis of content links on Facebook. ISOJ: The Official Research Journal ofInternational Symposium on Online Journalism, 1(2). Available from www.academia.edu

Bennett, W. L. \&Iyengar, S. (2008). A New Era of Minimal Effects?The Changing Foundations of Political Communication.Journal of Communication,58 (4), 707-731. doi:10.1111/j.1460-2466.2008.00410.x

Bimber, B. (2003). Information and American Democracy: Technology in the Evolution of Political Power. New York: Cambridge University Press.

Bimber, B, \& Davis, R. (2003).Campaigning Online: The Internet in U.S. Elections. New York: Oxford University Press.

Boyatzis, R. E. (1998). Transforming Qualitative Information: Thematic analysis and code development. Thousand Oaks: SAGE Publications.

Boyd, D. M., \& Ellison, N. B. (2007). Social network sites: Definition, history, and scholarship. Journal of Computer-Mediated Communication, 13 (1), 210-230. doi:10.1111/j.1083-6101.2007.00393.x

Brundidge, J. (2007). The Internet and the Transformation of Political Participation: Evolution or Revolution?. Unpublished paper presented at National Communication Association 2007 Annual Convection, Chicago. Available from http://web.ebscohost.com 
Brundidge, J. (2010). Encountering "Difference" in the Contemporary Public Sphere: The Contribution of the Internet to the Heterogeneity of Political Discussion Networks.Journal of Communication, 60 (4), 680-700. doi: 10.1111/j.14602466.2010.01509.x

Calenda, D. \&Mosca, L. (2007). The political use of the internet: Some insights from two surveys of Italian students. Information, Communication \& Society, 10 (1), 29-47. doi:10.1080/13691180701193028

Cavanaugh, J. W. (2000). E-Democracy: Thinking about the impact of technology on civic life. National Civic Review, 89 (3), 229-234. doi:10.1002/ncr.89305

Chaffee, S. H., Saphir, M. N., Graf, J., Sandvig, C., \& Hahn, K. S. (2001). Attention to Counter-Attitudinal Messages in a State Election Campaign. Political Communication, 18(3), 247-272. doi:10.1080/10584600152400338

Christy, C. A. (1987). Sex differences in political participation: Processes of change in fourteen nations. New York: Praeger Publisher.

Cornfield, M. (2005). The Internet and campaign 2004.Pew Internet and American Life Project.Available from www.pewinternet.org

Council of Europe, Committee of Ministers. (2009). Recommendation CM/Rec(2009)1 of the Committee of Ministers to member states on electronic democracy (e-democracy). Available from: www.coe.int

Dutta-Bergman, M. \&Wonjun, C. (2005).The relationship between online political participation and traditional political participation: The theory of channel complementarity. Unpublished paper presented at the International Communication Association 2005 Annual Meeting, New York. Available from http://web.ebscohost.com

Fallows, J. (2002). He's got mail. New York Review of Books, 49(4), 4-7.

Festinger, L. (1957). A theory of cognitive dissonance. Stanford, CA: Stanford University Press

Frey, D. (1986). Recent research on selective exposure to information.Advances in Experimental Social Psychology, 19(1), 41-80. doi:10.1016/S0065-2601(08)60212-9

Garrett, R. K. (2009). Politically motivated reinforcement seeking: Reframing the selective exposure debate. Journal of Communication, 59(4), 676-699. doi:10.1111/j.14602466.2009.01452.x 
Hardy, B. W., Jamieson, K. H. \&Winneg, K. (2009). Wired to fact: The role of the internet in identifying deception during the 2004 U.S. presidential campaign.In Chadwick, A. and Howard, P. N. (Eds).Routledge Handbook of Internet Politics. Abington: Routledge (pp. 131-143).

Hermida, A., Fletcher, F., Korrell, D. \& Logan, D. (2011).Your Friend as Editor: The Shift to the Personalized Social News Stream. Unpublished paper presented at The Future of Journalism Conference, Cardiff, Available from www0.caerdydd.ac.uk

Holbert, R. L., Garrett, R. K. \& Gleason, L. S. (2010).A New Era of Minimal Effects?A Response to Bennett and Iyengar.Journal of Communication, 60 (1), 15-34. doi:10.1111/j.1460-2466.2009.01470.x

Kenski, K. \& Stroud, N. J. (2006).Connections Between Internet Use and Political Efficacy, Knowledge, and Participation. Journal of Broadcasting \& Electronic Media, 50 (2), 173-192. doi:10.1207/s15506878jobem5002_1

Kim, Y. (2011). The contribution of social network sites to exposure to political difference:

The relationships among SNSs, online political messaging, and exposure to crosscutting perspectives. Computers in Human Behavior, 27 (2), 971-977. doi:10.1016/j.chb.2010.12.001

Klapper, J. T. (1960). The effects of mass communication. New York: Free Press.

Lampe, C., Vitak, J., Gray, R., \& Ellison, N. (2012).Perceptions of Facebook's value as an information source. Proceedings of the 2012 Annual Conference on Human Factors in Computing Systems. New York: ACM, 3195-3204. doi:10.1145/2207676.2208739

Lerman, K. \&Ghosh, R. (2010). Information Contagion: an Empirical Study of the Spread of News on Digg and Twitter Social Networks. Proceedings of $4^{\text {th }}$ International Conference on Weblogs and Social Media. Menlo Park, California: The AAAI Press. Available from http://arxiv.org

Lilliefors, H. W. (1967). On the Kolmogorov-Smirnov Test for Normality with Mean and Variance Unknown.Journal of the American Statistical Association, 62 (318), 399402.

McNair, B. (2009). The internet and the changing global media environment.In Chadwick, A. and Howard, P. N. (Eds.) Routledge Handbook of Internet Politics. Abington: Routledge (pp. 217-229).

Meyer, K. (2012). Tearing Apart The Online Electorate: How the Social Media of the Political Parties Polarizes the American Public. Proceedings of The National 
Conference On Undergraduate Research (NCUR) 2012. Ogden, Utah. Available from www.ncurproceedings.org

Milakovich, M. E. (2010). The Internet and Increased Citizen Participation in Government.eJournal of eDemocracy and Open Government, 2 (1), 1-9. Available from www.jedem.org

Nie, N., Miller, D., Golde, S., Butler, D., \&Winneg, K. (2010).The World Wide Web and the U.S. Political News Market.American Journal of Political Science, 54 (2), 428-439. doi:10.1111/j.1540-5907.2010.00439.x

Percy Smith, J. (1995). Digital Democracy: Information and Communication Technologies in Local Politics. Research Report No. 14. London: Commissionfor Local Democracy.

Polat, R. K. (2005). The Internet and Political Participation: Exploring the Explanatory Links. European Journal of Communication, 20 (4), 435-459. doi:10.1177/0267323105058251

Quintelier, E. (2007). Differences in political participation between young and old people: A representative study of the differences in political participation between young and old people. Contemporary Politics, 13(2), 165-180. doi:1080/13569770701562658

Rainie, L. \& Smith, A. (2012).Politics on Social Networking Sites.The Pew Research Center's Internet \& American Life Project. Available from http://pewinternet.org

Rainie, L., Smith, A., Lehman-Schlozman, K., Brady, H. \&Verba, S. (2012). Social Media and Political Engagement.The Pew Research Center's Internet \& American Life Project. Available from http://pewinternet.org

Shah, D. V., McLeod, J. M. \& Yoon, S.-H. (2001). Communication, Context, and Community An Exploration of Print, Broadcast, and Internet Influences. Communication Research, 28 (4), 464-506. doi:10.1177/009365001028004005

Socialbakers.2013. Facebook Statistics by Country. Available from www.socialbakers.com Sunstein, C. R. (2001). Republic.com. Princeton, NJ: Princeton University Press.

Stroud, N. J. (2008). Media Use and Political Predispositions: Revisiting the Concept of Selective Exposure. Political Behavior, 30(3), 341-366. doi:10.1007/s11109-0079050-9

Tewksbury, D., Weaver, A. J., \&Maddex, B. D. (2001).Accidentally informed: News exposure on the World Wide Web.Journalism and Mass Communication Quarterly, 78 (3), 533-554. doi:10.1177/107769900107800309 
Tewksbury, D. \&Rittenberg, J. (2012).News on the Internet: Information and Citizenship in the 21st Century. Oxford: Oxford University Press.

Tewksbury, D. \&Rittenberg, J. (2009). Online news creation and consumption: implications for modern democracies. In Chadwick, A. and Howard, P. N. (Eds.) Routledge Handbook of Internet Politics. Abington: Routledge (pp. 186-200).

Tichenor, P. A., Donohue, G. A. \&Olien, C. N. (1970).Mass media flow and differential growth in knowledge.Public Opinion Quarterly, 34 (2), 159-170.

Vickery, J. (2009). Facebook, ideological difference, and weak ties: A qualitative analysis. Unpublished paper presented at The Association of Internet Research Conference 10.0, Milwaukee. Available from www.academia.edu

Vitak, J., Zube, P., Smock, A., Carr, C., Ellison, N., \& Lampe, C. (2009)."Poking" People to Participate: Facebook and Political Participation in the 2008 Election. Unpublished paper presented attheInternational Communication Association 2009 Annual Meeting, Chicago. Available from http://web.ebscohost.com

Webster, J. G. (2007). Diversity of exposure.In Napoli, P. M. (Ed.) Media diversity and localism: Meaning and metrics. Mahwah, NJ: Erlbaum (pp. 309-326).

Wojcieszak, M., \&Mutz, D. (2009). Online groups and political deliberation: Does the Internet facilitate exposure to disagreement?.Journal of Communication, 59 (1), 40-56. doi:10.1111/j.1460-2466.2008.01403.x

Zube, P. J., Lampe, C. \& Lin, J. (2009).Web 2.Step-Flow: Social Networking Sites and Political Information. Unpublished paper presented at the Annual meeting of the NCA $95^{\text {th }}$ Annual Convention, Chicago.Available from www.allacademic.com 